\title{
OPTIMIZATION OF PRODUCT TRANSFER WITH CONSTRAINT IN ROBOTIC CELL USING SIMULATION
}

\author{
Masmoudi, F.; Masmoudi, Y. \& Maalej, Y. A. \\ Mechanics, modelling and production Laboratory (U2MP) \\ Engineering school of Sfax, BP. W, 3038 Sfax, Tunisia \\ E-Mail: faouzi.masmoudi@enis.rnu.tn
}

\begin{abstract}
This article deals with simulation modelling of a flexible manufacturing cell. Our purpose is the optimization of a robot cycle that transfers products in the cell. We consider the productivity as performance criterion. An analytical survey is developed and validated by simulation results. These results permit to get an aided adequate decision and a large reactivity facing the changes of products operated in a flexible manufacturing cell. A constraint of flow time of products on machines has been considered in the model, the results of the simulation allowed to eliminate invalid cycles with this constraint and to classify the remaining cycles according to their shortest cycle times.

(Received in September 2005, accepted in March 2006. This paper was with the authors 2 months for 2 revisions.)
\end{abstract}

Key Words: Robotic Cell, Cycle, Optimization, Simulation, Constraint

\section{INTRODUCTION}

The optimization of productivity in manufacturing cells is mainly influenced by the process of transfer between machines. The most important objective is to increase the flow of products in the manufacturing system. The industrial robots have the faculty to be flexible; they allow doing a variety of transfer cycles and can repeat a sequence as much time as the production needs. The aim of this work is to select, among the different possible cycles, the shortest cycle that minimizes the time allocated to the transfer of products between machines while respecting the technological constraints of production.

The problem of selecting the robot transfer cycle made the object of various works. Conditions, hypotheses and methods of treatment vary from one case to another. N. Brauner and G. Finkes analyzed, in [1] and [2] a manufacturing system working in flow shop, the conjecture claiming that the maximum rate of production is obtained by repeating the cycle of production of a one piece that spend the shortest time. They prove that this conjecture is valid for the case of two or three machines but not more valid for four machines and more.

S.P. Sethi, C. Sriskandarajah, G. Sorger, J. Blazewicz, and W. Kubiak in [3], studied the different cycles of the robot. They suppose that the loading and unloading times of pieces on the different machines are identical and the displacement times of the robot between machines are proportional. They propose in this case a tree for the choice of the cycle in a three machines cell.

H. Kammoun, N. G. Hall and C. Sriskandarajah treated the problem of organization in robotic cells working in flow shop and producing a similar product family with a central robot having the possibility to make a linear movement. They propose in [4], an algorithm for the choice of the best cycle in the case of two machines cell, they use some heuristic methods in [5] for the case of three machines production cell, and study the problem of minimization of the average steady-state cycle time in [6] and [7]. 
A. Soukhal and P. Martineau presented an integer programming model to determine the sequence of jobs that minimizes the makespan criterion in [8]; they propose a genetic algorithm for large size problem without considering the transportation time.

In this paper, we propose to take the survey of cycles of the robot in a cell of production while introducing a new modelling approach, in order to solve this problem by simulation. Working constraints of manufacturing cell will be added to basic hypotheses allowing being nearest to the industrial reality. A case study will therefore be presented.

We define, in this work, a cycle as the whole useful interventions of the robot in the manufacturing system, loaded or unloaded, like motions, operations or waiting, such:

- The system produces at least one piece,

- The system recovers its initial state after finishing.

\section{PRESENTATION OF THE PROPOSED MODEL}

We consider a production cell with $m$ machines, implanted in a circular disposition and served by a central robot (Fig.1).

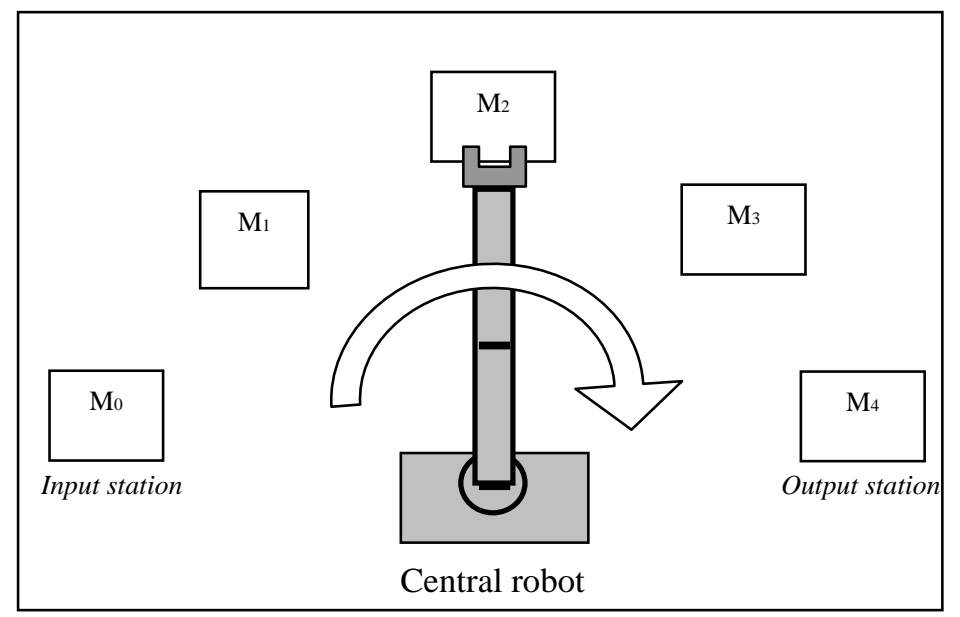

Figure1: Robotic cell of production in flow shop.

Machines are designated by $\mathrm{M}_{1}, \mathrm{M}_{2}, \ldots, \mathrm{M}_{\mathrm{m}}$ where $m$ is the number of effective machine. We add two stations $\mathrm{M}_{0}$ and $\mathrm{M}_{\mathrm{m}+1}$ for respectively the entrance and the exit of products. The cell is considered working in flow shop.

We deal with a production of repetitive shares of identical pieces; therefore, the raw material is considered available in infinite quantity in $\mathbf{M}_{0}$. A chosen piece in $\mathbf{M}_{0}$ will be transferred successively to $\mathrm{M}_{1}, \mathrm{M}_{2}, \ldots, \mathrm{M}_{\mathrm{m}}$ where it get a transformation, until reaching the station of exit $\mathrm{M}_{\mathrm{m}+1}$ supposed to have an unlimited storage capacity. We consider also that the central robot can only operate a one piece a time, and machines don't arrange any intermediate storage zones.

To describe the system, we developed a model in which we adopt the state vector presentation:

where:

$$
E=\left(x_{1}, x_{2}, \ldots, x_{m}, \mathrm{~A}_{\mathrm{i}}\right) \quad i=0,1,2, \ldots, m
$$

- $x_{i}$ : designates the state of the $\mathrm{M}_{\mathrm{i}}$ machine: $\left(x_{i}=0\right.$ if the $\mathrm{M}_{\mathrm{i}}$ machine is free; $x_{i}=1$ if the $\mathrm{M}_{\mathrm{i}}$ machine is busy),

- $\mathrm{A}_{\mathrm{i}}$ : designates the activity that the robot gets ready to do:

$1 /$ the free robot takes the piece at $\mathrm{M}_{\mathrm{i}}$

$2 /$ the robot transfers this piece from $M_{i}$ to $M_{i+1}$

3 / the robot loads this piece on $\mathrm{M}_{\mathrm{i}+1}$ 
The representation of a cycle is done by a succession of state vectors. The observation of two successive vectors permits to identify the previous position of the robot.

\section{TRANSFER CYCLES}

\subsection{Notation}

The following notation is used to describe the robotic cell:

$m \quad$ : the number of machines in the cell

$\mathrm{M}_{1}, \mathrm{M}_{2}, \ldots, \mathrm{M}_{\mathrm{m}}$ : machines of the robotic production cell working in flow shop, they are presented in the order of operations of transformation

$a, b, c, \ldots \quad:$ the operating times respectively on machines $\mathrm{M}_{1}, \mathrm{M}_{2}, \mathrm{M}_{3}, \ldots$

$d_{i, j}=d_{j, i} \quad$ : time spent by the robot to pass between two machines $\mathrm{M}_{\mathrm{i}}$ and $\mathrm{M}_{\mathrm{j}}$

$e_{1}$

: time spent by the robot to take a piece at the entrance station $\left(\mathrm{M}_{0}\right)$

$e_{2 i}$

$e_{2 i+1}$

$e_{2 m+1}$

$w_{i}$

$S_{j}$

$C_{j}$

$T C_{j}$

: time spent by the robot to load a piece on the $\mathrm{M}_{\mathrm{i}}$ machine with $i \neq 0$

: time spent by the robot to unload a piece at the $M_{i}$ machine

: time spent by the robot to free a piece to the stock of exit (station $\mathrm{M}_{\mathrm{m}+1}$ )

: time of a possible waiting of the robot on the $\mathrm{M}_{\mathrm{i}}$ machine

: sequence of transfer

: cycle corresponding to the $S_{j}$ sequence

We put on the following simplifying hypotheses $\mathbf{H}$ :

$-d_{i, i+1}=d_{i+1, i}=d$ for $i=0,1, \ldots, m$

(The robot displacement time between any pair of adjacent machine is the same.)

- $d_{i, j}=|i-j| \cdot d \quad$ for $i, j=0,1, \ldots, m+1$

(Displacement between any two machines is accomplished by traversing a sequence of intermediate adjacent machines.)

$-e_{1}=e_{2 i}=e_{2 i+1}=e_{2 m+1}=e$

(Each load and unload operation performed by the robot takes the same amount of time.)

We can say that:

- Every activity $A_{i}$ must occur only one time during a cycle,

- The robot makes a waiting $w_{i}$ at every $\mathrm{M}_{\mathrm{i}}$ machine, the value of this waiting varies from zero (without waiting), until the operative time on this machine,

- It is required to make at most one displacement of the robot to start a new activity (the number of activities is $(m+1))$.

The cycle time verifies:

and

$$
T C \geq \sum_{i=0}^{m} e_{2 i+1}+\sum_{i=0}^{m} d_{i, i+1}+\sum_{i=1}^{m+1} e_{2 i}+\sum_{i=1}^{m} w_{i}
$$

$$
T C \leq \sum_{i=0}^{m} e_{2 i+1}+\sum_{i=0}^{m} d_{i, i+1}+\sum_{i=1}^{m+1} e_{2 i}+\sum_{i=1}^{m} w_{i}+(m+1) \max \left\{d_{i, j}\right\}_{0 \leq i, j \leq m+1}
$$

By using the simplifying hypotheses $\mathbf{H}$ these relations become:

$$
T C \geq 2(m+1) e+(m+1) d+\sum_{i=1}^{m} w_{i}
$$

and

$$
T C \leq 2(m+1) e+(m+1)(m+2) d+\sum_{i=1}^{m} w_{i}
$$


In the next sections, we present the case of three machines manufacturing cells.

\subsection{Transfer cycles in three-machine cell}

To get the real first cycle of transfer, the cell passes by a transitory phase that permits to pass from the state "All machine free" to the initial state correspondent to every cycle. Considering the type of production chosen (serial), these transitory phases are ignored in the survey of cycles. We are interested in the steady phases that let us recognize cycles.

For the presentation of a cycle under succession of state vectors, we start with the state where a piece is going to be dropped from the production system (vector including the Am activity), this in the objective to be sure that we passed the transitory phase mentioned above.

Therefore, to identify all possible cycles in the case of a three-machine cell, we start the representation of a cycle with the state where a piece finished on $\mathrm{M}_{3}$ is going to be freed on the products output station. Thus, the possible cycles will be:

- $\mathrm{C}_{1}:\left(0,0,1, \mathrm{~A}_{3}\right) ;\left(0,0,0, \mathrm{~A}_{0}\right) ;\left(1,0,0, \mathrm{~A}_{1}\right) ;\left(0,1,0, \mathrm{~A}_{2}\right)$

- $\mathrm{C}_{2}:\left(0,1,1, \mathrm{~A}_{3}\right) ;\left(0,1,0, \mathrm{~A}_{0}\right) ;\left(1,1,0, \mathrm{~A}_{2}\right) ;\left(1,0,1, \mathrm{~A}_{1}\right)$

- $\mathrm{C}_{3}:\left(0,1,1, \mathrm{~A}_{3}\right) ;\left(0,1,0, \mathrm{~A}_{2}\right) ;\left(0,0,1, \mathrm{~A}_{0}\right) ;\left(1,0,1, \mathrm{~A}_{1}\right)$

- $\mathrm{C}_{4}:\left(1,0,1, \mathrm{~A}_{3}\right) ;\left(1,0,0, \mathrm{~A}_{1}\right) ;\left(0,1,0, \mathrm{~A}_{2}\right) ;\left(0,0,1, \mathrm{~A}_{0}\right)$

- $\mathrm{C}_{5}:\left(1,0,1, \mathrm{~A}_{3}\right) ;\left(1,0,0, \mathrm{~A}_{1}\right) ;\left(0,1,0, \mathrm{~A}_{0}\right) ;\left(1,1,0, \mathrm{~A}_{2}\right)$

- $\mathrm{C}_{6}:\left(1,1,1, \mathrm{~A}_{3}\right) ;\left(1,1,0, \mathrm{~A}_{2}\right) ;\left(1,0,1, \mathrm{~A}_{1}\right) ;\left(0,1,1, \mathrm{~A}_{0}\right)$

Sequences of transfer are represented by the following figures (Fig. 2 to Fig. 4):

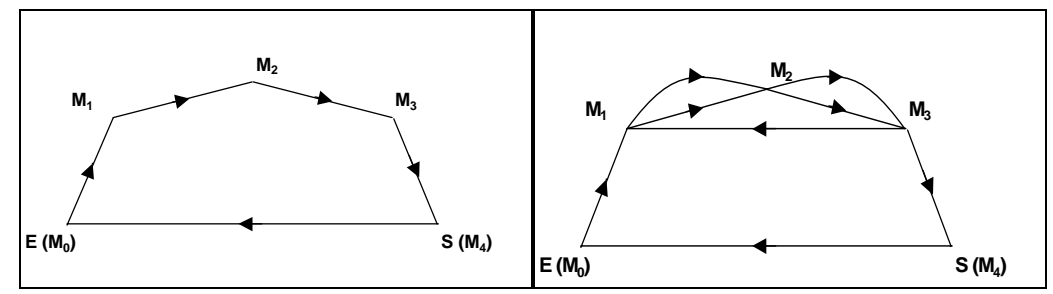

$\mathrm{S}_{1}: \frac{\left(0,0,0, \mathrm{~A}_{0}\right) ;\left(1,0,0, \mathrm{~A}_{1}\right) ;\left(0,1,0, \mathrm{~A}_{2}\right)}{\text { Transitory phase }} ; \frac{\left(0,0,1, \mathrm{~A}_{3}\right) ;\left(0,0,0, \mathrm{~A}_{0}\right) ;\left(1,0,0, \mathrm{~A}_{1}\right) ;\left(0,1,0, \mathrm{~A}_{2}\right)}{\text { first cycle }} \ldots$

$\left.\mathrm{S}_{2}:\left(0,0,0, \mathrm{~A}_{0}\right) ;\left(1,0,0, \mathrm{~A}_{1}\right) ;\left(0,1,0, \mathrm{~A}_{0}\right) ;\left(1,1,0, \mathrm{~A}_{2}\right) ;\left(1,0,1, \mathrm{~A}_{1}\right) ; 0,0,1,1, \mathrm{~A}_{3}\right) ;\left(0,1,0, \mathrm{~A}_{0}\right) ;\left(1,1,0, \mathrm{~A}_{2}\right) ;\left(1,0,1, \mathrm{~A}_{1}\right) \ldots$

Transitory phase first cycle

Figure 2: Sequences of transfer $\mathrm{S}_{1}$ and $\mathrm{S}_{2}$.

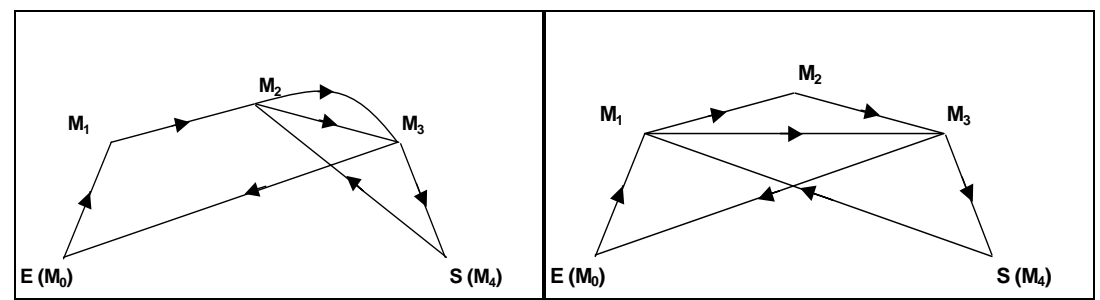

$\left.\mathrm{S}_{3}:\left(0,0,0, \mathrm{~A}_{0}\right) ;\left(1,0,0, \mathrm{~A}_{1}\right) ;\left(0,1,0, \mathrm{~A}_{2}\right) ;\left(0,0,1, \mathrm{~A}_{0}\right) ;\left(1,0,1, \mathrm{~A}_{1}\right) ; 0,1,1, \mathrm{~A}_{3}\right) ;\left(0,1,0, \mathrm{~A}_{2}\right) ;\left(0,0,1, \mathrm{~A}_{0}\right) ;\left(1,0,1, \mathrm{~A}_{1}\right) \ldots$ Transitory phase first cycle

$\left.\mathrm{S}_{4}:\left(0,0,0, \mathrm{~A}_{0}\right) ;\left(1,0,0, \mathrm{~A}_{1}\right) ;\left(0,1,0, \mathrm{~A}_{2}\right) ;\left(0,0,1, \mathrm{~A}_{0}\right) ;\left(1,0,1, \mathrm{~A}_{3}\right) ;\left(1,0,0, \mathrm{~A}_{1}\right) ;\left(0,1,0, \mathrm{~A}_{2}\right) ;\left(0,0,1, \mathrm{~A}_{0}\right)\right] \ldots$ Transitory phase first cycle

Figure 3: Sequences of transfer $\mathrm{S}_{3}$ and $\mathrm{S}_{4}$. 


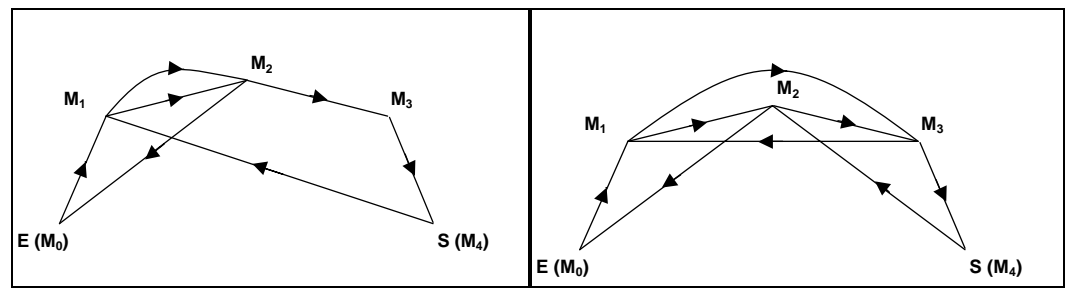

\section{$\mathrm{S}_{5}:\left(0,0,0, \mathrm{~A}_{0}\right) ;\left(1,0,0, \mathrm{~A}_{1}\right) ;\left(0,1,0, \mathrm{~A}_{0}\right) ;\left(1,1,0, \mathrm{~A}_{2}\right) ;\left(1,0,1, \mathrm{~A}_{3}\right) ;\left(1,0,0, \mathrm{~A}_{1}\right) ;\left(0,1,0, \mathrm{~A}_{0}\right) ;\left(1,1,0, \mathrm{~A}_{0}\right)$ \\ Transitory phase \\ first cycle \\ $\mathrm{S}_{6}:\left(0,0,0, \mathrm{~A}_{0}\right) ;\left(1,0,0, \mathrm{~A}_{1}\right) ;\left(0,1,0, \mathrm{~A}_{0}\right) ;\left(1,1,0, \mathrm{~A}_{2}\right) ;\left(1,0,1, \mathrm{~A}_{1}\right) ;\left(0,1,1, \mathrm{~A}_{0}\right) ;\left(1,1,1, \mathrm{~A}_{3}\right) ;\left(1,1,0, \mathrm{~A}_{2}\right) ;\left(1,0,1, \mathrm{~A}_{1}\right) ;\left(0,1,1, \mathrm{~A}_{0}\right)$ \\ Transitory phase first cycle}

Figure 4: Sequences of transfer $S_{5}$ and $S_{6}$.

\section{RESOLUTION}

\subsection{Analytic resolution}

The detail of the cycle time is given as follows:

In the case of simplifying hypotheses $\mathbf{H}$, cycle time become:

- $T C_{1}=2 \alpha+a+b+c$

- $T C_{2}=\alpha+\operatorname{Max}\{\beta, b, \beta / 2+a, \beta / 2+c, a / 2+b / 2+c / 2\}$

- $T C_{3}=\alpha+\operatorname{Max}\{a+b+\alpha / 2 ; \alpha+2 d+a ; c\}$

- $T C_{4}=\alpha+\operatorname{Max}\{\beta+b, \alpha / 2+a+b, \alpha / 2+b+c\}$

- $T C_{5}=\alpha+\operatorname{Max}\{a, \alpha+c+2 d, \alpha / 2+b+c\}$

- $T C_{6}=\alpha+\operatorname{Max}\{\beta, a, b, c\}$

where $\alpha=4 d+4 e$ and $\beta=8 d+4 e$

As the calculation in the cycle time is similar in each of the cases, we will illustrate the procedure for just one case; let's take the case of the sequence $S_{3}$ cycle for example. In the case of the simplifying hypotheses, the cycle time is given by:

$$
\mathrm{TC}_{3}=8 e+10 d+w_{2}+w_{3}+a
$$

where $\mathrm{w}_{2}$ and $\mathrm{w}_{3}$ are respectively waiting time at $\mathrm{M}_{2}$ and $\mathrm{M}_{3}$ :

$$
\begin{aligned}
& w_{2}=\operatorname{Max}\left\{b-2 e-4 d-w_{3} ; 0\right\} \\
& w_{3}=\operatorname{Max}\{c-4 e-6 d-a ; 0\}
\end{aligned}
$$

In this case:

$$
\begin{aligned}
T_{3} & =8 e+10 d+a+\operatorname{Max}\left\{b-2 e-4 d-w_{3} ; 0\right\}+\operatorname{Max}\{c-4 e-6 d-a ; 0\} \\
& =\alpha+\beta-2 d+a+\operatorname{Max}\left\{b-\beta / 2-w_{3} ; 0\right\}+\operatorname{Max}\{c-\beta+2 d-a ; 0\} \\
& =\alpha+\operatorname{Max}\{b-\beta / 2-\operatorname{Max}\{\beta-2 d+a ; c\} ; 0\}+\operatorname{Max}\{\beta-2 d+a ; c\} \\
& =\alpha+\operatorname{Max}\{a+b+\beta / 2-2 d-\operatorname{Max}\{\beta-2 d+a ; c\} ; 0\}+\operatorname{Max}\{\beta-2 d+a ; c\} \\
& =\alpha+\operatorname{Max}\{a+b+\beta / 2-2 d ; \operatorname{Max}\{\beta-2 d+a ; c\}\} \\
& =\alpha+\operatorname{Max}\{a+b+\beta / 2-2 d ; \beta-2 d+a ; c\} \\
T_{3} & =\alpha+\operatorname{Max}\{a+b+\alpha / 2 ; \alpha+2 d+a ; c\}
\end{aligned}
$$

Some similar reasoning can be made for the other cycles; the analytical comparison between the cycle times is difficult even in the case of the simplifying hypotheses. 


\subsection{Resolution by simulation}

The problem becomes difficult to solve analytically with no simplifying hypotheses $\mathbf{H}$, so we adopt a decision help tool that provides the optimal cycle that minimizes the cycle time while taking account of work conditions. We have prepared a program in Excel that permits to calculate the different cycle times and to provide the optimal cycle for given data and conditions.

Waiting times are basically important in the calculation of the cycle time. They are given for the six possible cycles by:

\section{Cycle 1:}

$$
w_{1}=a \quad w_{2}=b \quad w_{3}=c
$$

\section{Cycle 2:}

- $w_{1}=\operatorname{Max}\left(a-\left(d_{04}+e_{1}+d_{01}+e_{2}+d_{02}+b+e_{5}+d_{23}+e_{6}+d_{13}\right) ; 0\right)$

- $w_{2}=b$

- $w_{3}=\operatorname{Max}\left(c-\left(d_{13}+w_{1}+e_{3}+d_{12}+e_{4}+d_{23}\right) ; 0\right)$

\section{Cycle 3:}

- $w_{1}=a$

- $w_{2}=\operatorname{Max}\left(b-\left(d_{23}+w_{3}+e_{7}+d_{34}+e_{8}+d_{24}\right) ; 0\right)$

- $w_{3}=\operatorname{Max}\left(c-\left(d_{03}+e_{1}+d_{01}+e_{2}+a+e_{3}+d_{12}+e_{4}+d_{23}\right) ; 0\right)$

\section{Cycle 4:}

- $w_{1}=\operatorname{Max}\left(a-\left(d_{13}+w_{3}+e_{7}+d_{34}+e_{8}+d_{14}\right) ; 0\right)$

- $w_{2}=b$

- $w_{3}=\operatorname{Max}\left(c-\left(d_{03}+e_{1}+d_{01}+e_{2}+d_{13}\right) ; 0\right)$

\section{Cycle 5:}

- $w_{1}=\operatorname{Max}\left(a-\left(d_{12}+w_{2}+e_{5}+d_{23}+e_{6}+c+e_{7}+d_{34}+e_{8}+d_{14}\right) ; 0\right)$

- $w_{2}=\operatorname{Max}\left(b-\left(d_{02}+e_{1}+d_{01}+e_{2}+d_{12}\right) ; 0\right)$

- $w_{3}=c$

\section{Cycle 6:}

- $w_{1}=\operatorname{Max}\left(a-\left(d_{13}+w_{3}+e_{2}+d_{34}+e_{8}+d_{24}+w_{2}+e_{5}+d_{23}+e_{6}+d_{13}\right) ; 0\right)$

- $w_{2}=\operatorname{Max}\left(b-\left(d_{02}+e_{1}+d_{01}+e_{2}+d_{13}+w_{3}+e_{7}+d_{34}+e_{8}+d_{24}\right) ; 0\right)$

- $w_{3}=\operatorname{Max}\left(c-\left(d_{13}+w_{1}+e_{3}+d_{12}+e_{4}+d_{02}+e_{1}+d_{01}+e_{2}+d_{13}\right) ; 0\right)$

\subsection{Simulation examples}

We present below data values in the corresponding cell and the obtained different cycle times.

Table I: Data and results in the $1^{\text {st }}$ Example.

\begin{tabular}{|c|c|c|c|c|c|c|c|c|c|c|c|c|c|c|c|c|c|c|c|c|c|}
\hline \multicolumn{22}{|c|}{ Data } \\
\hline Variable & $\mathbf{a}$ & $\mathbf{b}$ & c & $d_{01}$ & $d_{02}$ & $d_{03}$ & $d_{04}$ & $d_{12}$ & $d_{13}$ & $d_{14}$ & $d_{23}$ & $d_{24}$ & $d_{34}$ & $\mathbf{e}_{1}$ & $\mathbf{e}_{2}$ & e3 & $\mathbf{e}_{4}$ & e5 & e6 & $\mathbf{e}_{7}$ & es \\
\hline Time & 10 & 10 & 10 & 10 & 20 & 30 & 40 & 10 & 20 & 30 & 10 & 20 & 10 & 10 & 10 & 10 & 10 & 10 & 10 & 10 & 10 \\
\hline
\end{tabular}

\begin{tabular}{|l|l|l|l|l|l|}
\hline \multicolumn{5}{|c|}{ Results } \\
\hline TC $_{\mathbf{1}}$ & TC $_{\mathbf{2}}$ & TC $_{\mathbf{3}}$ & TC $_{\mathbf{4}}$ & TC $_{\mathbf{5}}$ & TC $_{\mathbf{6}}$ \\
\hline 200 & 250 & 220 & 220 & 200 & 210 \\
\hline
\end{tabular}

Cycles 1 and 5 have the shortest cycle times, therefore they are optimal. 
Table II: Data and results in the $2^{\text {nd }}$ Example.

\begin{tabular}{|c|c|c|c|c|c|c|c|c|c|c|c|c|c|c|c|c|c|c|c|c|c|}
\hline \multicolumn{22}{|c|}{ Data } \\
\hline & $\mathbf{a}$ & b & $\mathbf{c}$ & $d_{01}$ & d 02 & $\mathrm{~d}_{03}$ & $\mathrm{~d}_{04}$ & $d_{12}$ & $d_{13}$ & $d_{14}$ & $d_{23}$ & $\mathrm{~d}_{24}$ & $d_{34}$ & $\mathbf{e}_{1}$ & $\mathbf{e}_{2}$ & e & \begin{tabular}{|l|}
$\mathbf{e}_{4}$ \\
\end{tabular} & \begin{tabular}{|l|l}
$\mathbf{e}_{5}$ \\
\end{tabular} & \begin{tabular}{|l}
$\mathbf{e}_{6}$ \\
\end{tabular} & $\mathbf{e}_{7}$ & es \\
\hline Time & 100 & 150 & 70 & 15 & 30 & 45 & 60 & 15 & 30 & 45 & 15 & 30 & 15 & 10 & 10 & 10 & 10 & 10 & 10 & 10 & 10 \\
\hline
\end{tabular}

\begin{tabular}{|l|l|l|l|l|l|}
\hline \multicolumn{6}{|c|}{ Results } \\
\hline $\mathbf{T C}_{\mathbf{1}}$ & $\mathbf{T C}_{\mathbf{2}}$ & $\mathbf{T C}_{\mathbf{3}}$ & $\mathbf{T C}_{\mathbf{4}}$ & $\mathbf{T C}_{\mathbf{5}}$ & $\mathbf{T C}_{\mathbf{6}}$ \\
\hline 535 & 470 & 400 & 425 & 385 & 275 \\
\hline
\end{tabular}

Cycle 6 has the shortest cycle time, so it is the optimal one.

\section{SURVEY OF CYCLES WITH LIVING TIME CONSTRAINT}

In the previous study, we supposed that when the piece is accomplished on a machine $\mathrm{M}_{\mathrm{i}}$, it could wait the robot arrival to transfer it to the next station. The living time of the piece on the $\mathrm{M}_{\mathrm{i}}$ machine is without limit. In the situation when it is required to displace the piece to the next station in a definite delay (i.e., an interval of maximal living time of the piece on the $\mathrm{M}_{\mathrm{i}}$ machine), the choice of the cycle sequence is not only based on the minimal cycle time, but it becomes the choice of the shortest cycle that respects constraints of maximal living time. These constraints of stay time can be designated also by constraints on delays of availability of the robot to take the accomplished piece. This situation is met in surface treatment production, where stations of transformation are in general vats of chemicals or electrolytic solutions, pieces are immersed there during a definite time interval that must absolutely be respected to give to pieces the wished mechanical or chemical properties and otherwise, they would be damaged.

We will designate on the next, by margin on a $\mathrm{M}_{\mathrm{i}}$ machine the difference between the maximal tolerated living time and the operative time on this machine. It is the delay permitted to the robot to be available on the $\mathrm{M}_{\mathrm{i}}$ machine, ready to take the finished piece. We will note by $\boldsymbol{m}_{i}$ the margin corresponding to the operative time on the $\mathrm{M}_{\mathrm{i}}$ machine.

We should indicate here that the situation of constraints on delays is similar to the situation where there would be a risk of piece fall when the fixing system is disabled on the machine after the achievement of the operation. Margins will be then in this case equal to zero, or for more security, negative, i.e. the robot should be on the machine, ready to receive the piece, before the completion of the operation.

We are going to consider the general case of positive or negative margins. We reformulate the margin definition as the difference between the maximal tolerated living time of the piece on the machine without robot availability at the machine, and the operative time on this machine.

We use the following notions and definitions:

Lateness $\boldsymbol{r}_{i}$ : in first interpretation, it is the difference between the operative time on the $\mathrm{M}_{\mathrm{i}}$ machine and the time put by the robot between the piece loading and unloading on the same $\mathrm{M}_{\mathrm{i}}$ machine.

When it is negative, it concerns the time that a finished piece on the $\mathrm{M}_{\mathrm{i}}$ machine waits the return of the robot to displace it to the next station. The Lateness can be also positive; in this case, it is the time during which the robot, at the $\mathrm{M}_{\mathrm{i}}$ machine, waits the achievement of the operation.

We note that for waiting that do not correspond to an operative time we have:

$$
w_{i}=\operatorname{Max}\left(r_{i} ; 0\right)
$$


A cycle is said feasible when it satisfies all living time constraints, that is to say:

$$
\boldsymbol{r}_{\boldsymbol{i}}+\boldsymbol{m}_{\boldsymbol{i}} \geq \mathbf{0} \text { for all } i=1,2, \ldots, m \text {. }
$$

A cycle is selected when it is feasible and optimal at time, that is to say presenting a shortest cycle time among the feasible cycles. For a $\mathrm{M}_{\mathrm{i}}$ machine, different situations can occur, the following diagrams (Fig. 5) illustrate them:

Case 1 : Positive margin ; Positive lateness ; Operation always feasible

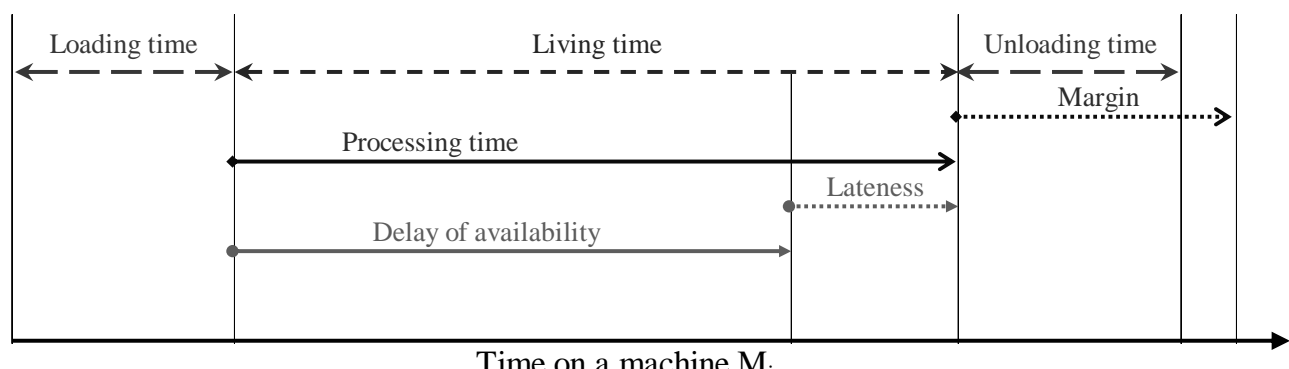

Case 2 : Positive margin ; Negative lateness ; Operation feasible

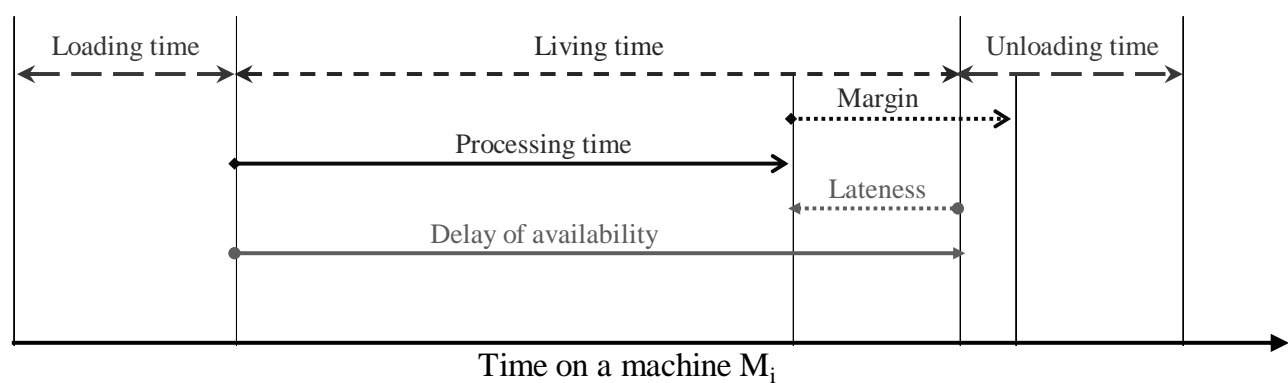

Case 3 : Positive margin ; Negative lateness ; Operation unfeasible

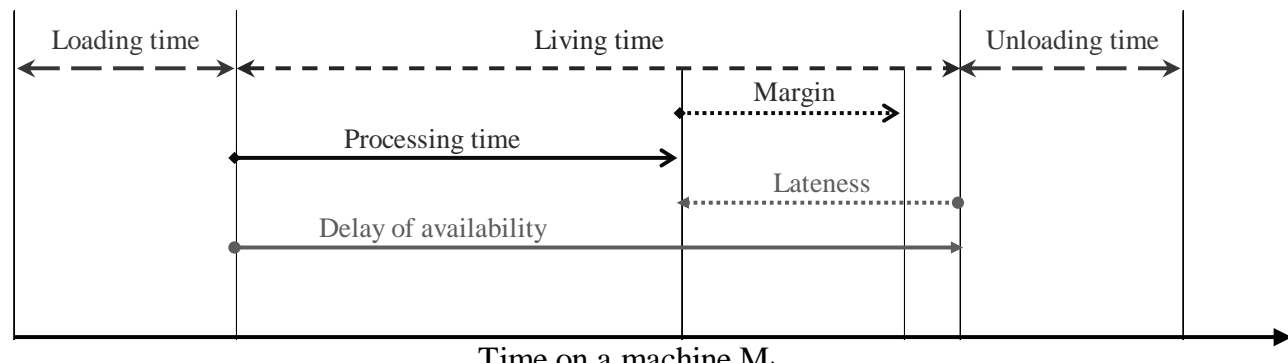

Time on a machine $\mathbf{M}_{\mathrm{i}}$

Case 4 : Negative margin ; Positive lateness ; Operation feasible

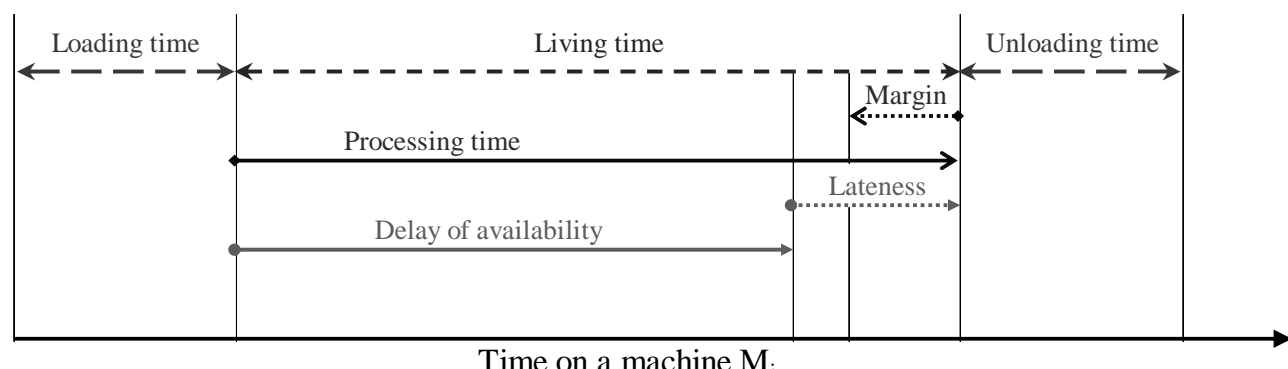

Time on a machine $\mathrm{M}_{\mathrm{i}}$ 
Case 5 : Negative margin ; Positive lateness ; Operation unfeasible

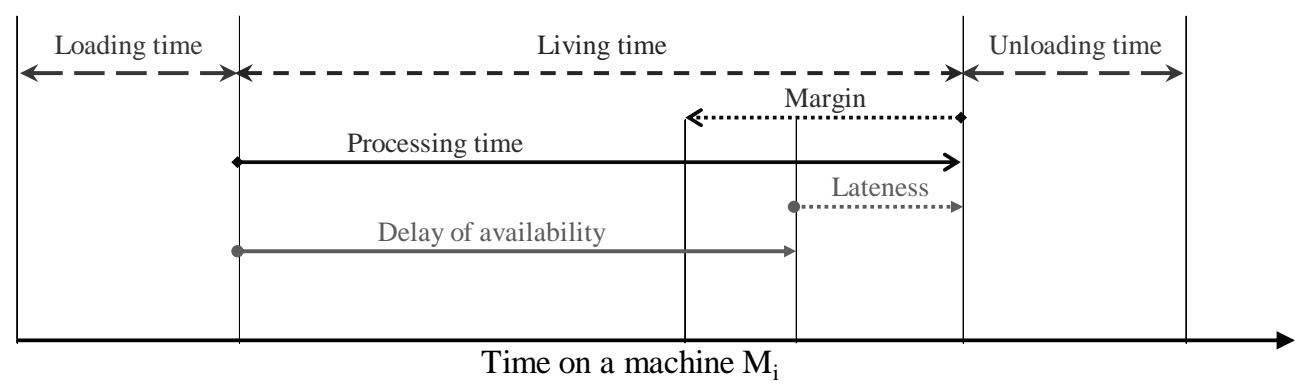

Case 6 : Negative margin ; Negative lateness ; Operation always unfeasible

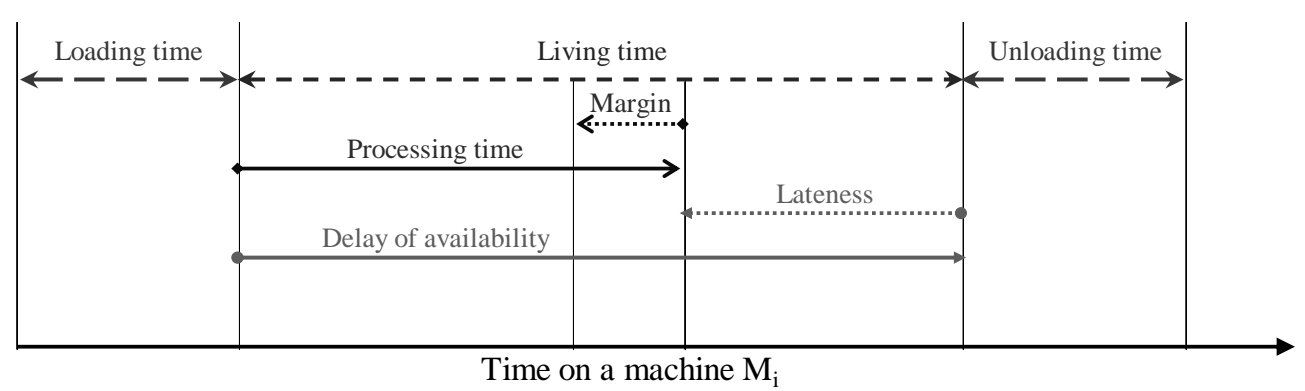

Figure 5: Different situations in cycles with living time constraint.

For a determined cycle, every machine can be before one of the previous situations according to production data. So that a cycle is feasible, it requires that all operations on the different machines are feasible.

We analyze in the next paragraph, the three machines cell case.

The lateness is given by:

Cycle 1: No lateness.

Cycle 2:

- $r_{1}=a-\left(d_{04}+e_{1}+d_{01}+e_{2}+d_{02}+b+e_{5}+d_{23}+e_{6}+d_{13}\right)$

- $r_{3}=c-\left(d_{13}+w_{1}+e_{3}+d_{12}+e_{4}+d_{23}\right)$

Cycle 3:

- $r_{2}=b-\left(d_{23}+w_{3}+e_{7}+d_{34}+e_{8}+d_{24}\right)$

- $r_{3}=c-\left(d_{03}+e_{1}+d_{01}+e_{2}+a+e_{3}+d_{12}+e_{4}+d_{23}\right)$

Cycle 4:

- $r_{1}=a-\left(d_{13}+w_{3}+e_{7}+d_{34}+e_{8}+d_{14}\right)$

- $r_{3}=c-\left(d_{03}+e_{1}+d_{01}+e_{2}+d_{13}\right)$

Cycle 5:

- $r_{1}=a-\left(d_{12}+w_{2}+e_{5}+d_{23}+e_{6}+c+e_{7}+d_{34}+e_{8}+d_{14}\right)$

- $r_{2}=b-\left(d_{02}+e_{1}+d_{01}+e_{2}+d_{12}\right)$

Cycle 6:

- $r_{1}=a-\left(d_{13}+w_{3}+e_{2}+d_{34}+e_{8}+d_{24}+w_{2}+e_{5}+d_{23}+e_{6}+d_{13}\right)$

- $r_{2}=b-\left(d_{02}+e_{1}+d_{01}+e_{2}+d_{13}+w_{3}+e_{7}+d_{34}+e_{8}+d_{24}\right)$

- $r_{3}=c-\left(d_{13}+w_{1}+e_{3}+d_{12}+e_{4}+d_{02}+e_{1}+d_{01}+e_{2}+d_{13}\right)$ 
We present first the procedure used to lead to the computer tool, which give the cycle(s) to choose and the reasoning that is reported in the file containing conditions and logical test, formulas of calculation and VB macro programming for data treatment.

We proceed as follows:

- We calculate the different cycle time (the file provides these data);

- We calculate the different Lateness times (relations that determine them are known);

- We compare them in relation to the corresponding margins (specified data);

- For every cycle satisfying constraints of margin we affect a logical value indicating that it is a feasible cycle;

- We sort out results by increasing cycle time (while using a VB macro);

- We reason downward way:

A cycle is selected when it is feasible and its cycle time is the shortest among the feasible cycles. Otherwise, a cycle is selected if it is feasible and cycles that precede them according to the order of the sorting, are not feasible or if it is feasible and its cycle time is already equal to a cycle retained.

This reasoning, translated on the computation worksheet, will lead precisely to feasible optimal cycle(s). The introducing of data in the corresponding field then the launching of the prepared macro will be sufficient to get the detailed results (The different times of cycles in the increasing order, the different delays, the feasibility of every cycle and the retained cycles).

\section{CASE STUDY}

The previous cycle review allows us to simulate replacing the handling system in a manufacture of panel ennoblement, which consists of rollers and conveyor manually ordered with operators, by an automatic handling system like a robot, and to put in evidence its interest.

The diagram of the production process is as follows (Fig. 6):

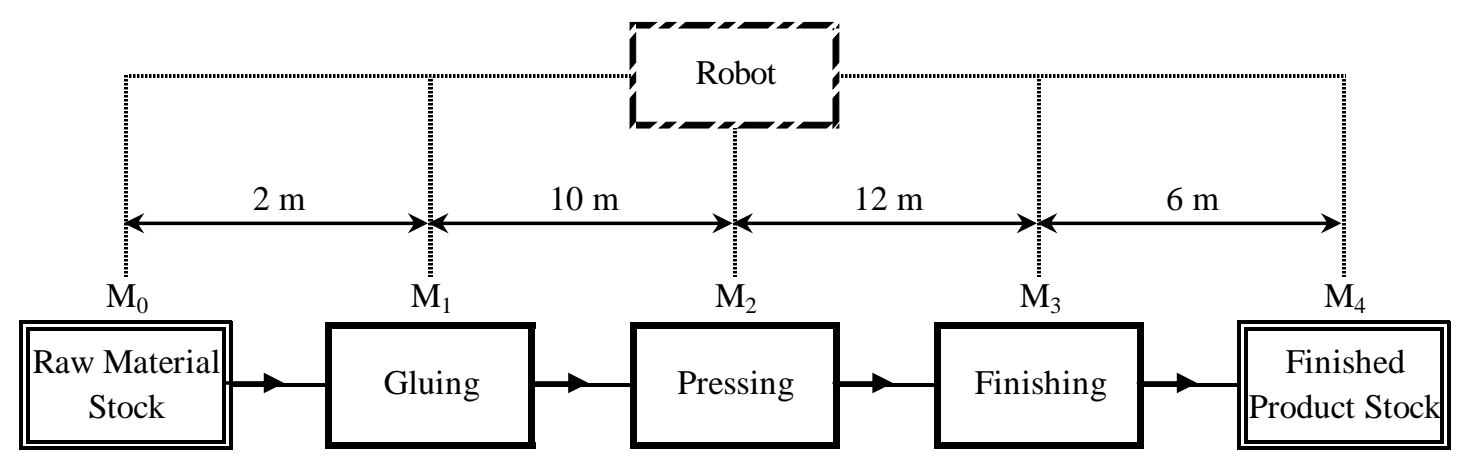

Figure 6: Diagram of the production process.

The stationary data of this system are the distances separating the different stations, the linear speed of the robot $(1 \mathrm{~m} / \mathrm{s})$, the other data for times are variable according to the type of product, its dimensions and the type of glue: the gluing time and finishing time are proportional to piece length, the open time of the glue is variable according to the glue type. This open time is considered as a constraint of limited positive margin. Another constraint is added after the operation of pressing that the robot must be ready to receive the piece before its evacuation from the hydraulic press. The feeding in raw material and the evacuation of the finished product are continuous, so we can consider these stocks with infinite capacity. 
We can use our model and the developed solution to make decision concerning the choice of the best cycle maximizing the productivity while respecting constraints.

We illustrate three cases on the following table (the time unit is a second). Note that in reality, there are various situations that must be treated one by one before the execution of the production.

Table III: Different cases data.

\begin{tabular}{|c|c|c|c|c|c|c|c|}
\hline \multicolumn{2}{|l|}{ Operation } & \multicolumn{2}{|c|}{$\begin{array}{c}\text { Case 1: } \\
\text { Piece length }=3,66 \mathrm{~m} \\
\text { Glue open time }=200 \mathrm{~s}\end{array}$} & \multicolumn{2}{|c|}{$\begin{array}{c}\text { Case 2: } \\
\text { Piece length }=2,05 \mathrm{~m} \\
\text { Glue open time }=180 \mathrm{~s}\end{array}$} & \multicolumn{2}{|c|}{$\begin{array}{c}\text { Case 3: } \\
\text { Piece length = 2,05 m } \\
\text { Glue open time }=60 \mathrm{~s}\end{array}$} \\
\hline & & Time & Margin & Time & Margin & Time & Margin \\
\hline Operation on $\mathrm{M}_{1}$ (Gluing) & $\mathrm{a}$ & 60 & 200 & 30 & 180 & 30 & 60 \\
\hline Operation on $\mathrm{M}_{2}$ (Pressing) & $\mathrm{b}$ & 180 & -120 & 180 & -20 & 180 & -20 \\
\hline Operation on $\mathrm{M}_{3}$ (Finishing) & C & 120 & 300 & 60 & 300 & 60 & 300 \\
\hline Displacement of $\mathrm{M}_{0}$ to $\mathrm{M}_{1}$ & $\mathrm{~d}_{01}$ & 2 & & 2 & & 2 & \\
\hline Displacement of $\mathrm{M}_{0}$ to $\mathrm{M}_{2}$ & $\mathrm{~d}_{02}$ & 12 & & 12 & & 12 & \\
\hline Displacement of $\mathrm{M}_{0}$ to $\mathrm{M}_{3}$ & $\mathrm{~d}_{03}$ & 24 & & 24 & & 24 & \\
\hline Displacement of $\mathrm{M}_{0}$ to $\mathrm{M}_{4}$ & $\mathrm{~d}_{04}$ & 30 & & 30 & & 30 & \\
\hline Displacement of $\mathrm{M}_{1}$ to $\mathrm{M}_{2}$ & $\mathrm{~d}_{12}$ & 10 & & 10 & & 10 & \\
\hline Displacement of $\mathrm{M}_{1}$ to $\mathrm{M}_{3}$ & $\mathrm{~d}_{13}$ & 22 & & 22 & & 22 & \\
\hline Displacement of $\mathrm{M}_{1}$ to $\mathrm{M}_{4}$ & $\mathrm{~d}_{14}$ & 28 & & 28 & & 28 & \\
\hline Displacement of $\mathrm{M}_{2}$ to $\mathrm{M}_{3}$ & $\mathrm{~d}_{23}$ & 12 & & 12 & & 12 & \\
\hline Displacement of $\mathrm{M}_{2}$ to $\mathrm{M}_{4}$ & $\mathrm{~d}_{24}$ & 18 & & 18 & & 18 & \\
\hline Displacement of $\mathrm{M}_{3}$ to $\mathrm{M}_{4}$ & $\mathrm{~d}_{34}$ & 6 & & 6 & & 6 & \\
\hline Taking a piece from RM Stock & $\mathrm{e}_{1}$ & 20 & & 20 & & 20 & \\
\hline Loading of a piece on $\mathrm{M}_{1}$ & $\mathrm{e}_{2}$ & 5 & & 5 & & 5 & \\
\hline Discharge of a piece of $\mathrm{M}_{1}$ & $\mathrm{e}_{3}$ & 5 & & 5 & & 5 & \\
\hline Loading of a piece on $\mathrm{M}_{2}$ & $\mathrm{e}_{4}$ & 5 & & 5 & & 5 & \\
\hline Discharge of a piece of $\mathrm{M}_{2}$ & $\mathrm{e}_{5}$ & 5 & & 5 & & 5 & \\
\hline Loading of a piece on $\mathrm{M}_{3}$ & $\mathrm{e}_{6}$ & 5 & & 5 & & 5 & \\
\hline Discharge of a piece of $\mathrm{M}_{3}$ & $\mathrm{e}_{7}$ & 5 & & 5 & & 5 & \\
\hline Liberation of a piece to PF Stock & $\mathrm{e}_{8}$ & 20 & & 20 & & 20 & \\
\hline
\end{tabular}

Table IV: Simulation Results.

\begin{tabular}{|c|c|c|c|c|c|c|c|c|}
\hline \multicolumn{3}{|c|}{ Results for case 1} & \multirow{2}{*}{$\begin{array}{c}\mathbf{r}_{\mathbf{1}} \\
-98\end{array}$} & \multirow{2}{*}{$\begin{array}{l}\mathbf{r}_{\mathbf{2}} \\
36\end{array}$} & \multirow{2}{*}{$\begin{array}{l}\mathbf{r}_{3} \\
17\end{array}$} & \multirow{2}{*}{$\begin{array}{c}\text { Feasibility } \\
\text { No }\end{array}$} & \multirow{2}{*}{$\begin{array}{c}\text { Choice } \\
\text { No }\end{array}$} & \multirow[t]{2}{*}{ Retained cycles } \\
\hline Cycle 6 & $\mathrm{TC}_{6}$ & 239 & & & & & & \\
\hline Cycle 3 & $\mathrm{TC}_{3}$ & 333 & & 91 & -39 & No & No & \\
\hline Cycle 4 & $\mathrm{TC}_{4}$ & 413 & -80 & & 47 & Yes & Yes & Cycle 4 \\
\hline Cycle 5 & $\mathrm{TC}_{5}$ & 413 & -294 & 131 & & No & No & \\
\hline Cycle 2 & $\mathrm{TC}_{2}$ & 434 & -176 & & 78 & Yes & No & \\
\hline Cycle 1 & $\mathrm{TC}_{1}$ & 502 & & & & Yes & No & \\
\hline \multicolumn{3}{|c|}{ Results for case 2} & $r_{1}$ & $\mathbf{r}_{2}$ & $\mathbf{r}_{3}$ & Feasibility & Choice & Retained cycles \\
\hline Cycle 6 & $\mathrm{TC}_{6}$ & 239 & -128 & 53 & -43 & Yes & Yes & Cycle 6 \\
\hline Cycle 3 & $\mathrm{TC}_{3}$ & 303 & & 91 & -69 & Yes & No & \\
\hline Cycle 5 & $\mathrm{TC}_{5}$ & 353 & -264 & 131 & & No & No & \\
\hline Cycle 4 & $\mathrm{TC}_{4}$ & 366 & -63 & & -13 & Yes & No & \\
\hline Cycle 2 & $\mathrm{TC}_{2}$ & 384 & -206 & & 18 & No & No & \\
\hline Cycle 1 & $\mathrm{TC}_{1}$ & 412 & & & & Yes & No & \\
\hline \multicolumn{3}{|c|}{ Results for case 3} & $\mathbf{r}_{1}$ & $\mathbf{r}_{2}$ & $\mathbf{r}_{3}$ & Feasibility & Choice & Retained cycles \\
\hline Cycle 6 & $\mathrm{TC}_{6}$ & 239 & -128 & 53 & -43 & No & No & \\
\hline Cycle 3 & $\mathrm{TC}_{3}$ & 303 & & 91 & -69 & Yes & Yes & Cycle 3 \\
\hline Cycle 5 & $\mathrm{TC}_{5}$ & 353 & -264 & 131 & & No & No & \\
\hline Cycle 4 & $\mathrm{TC}_{4}$ & 366 & -63 & & -13 & No & No & \\
\hline Cycle 2 & $\mathrm{TC}_{2}$ & 384 & -206 & & 18 & No & No & \\
\hline Cycle 1 & $\mathrm{TC}_{1}$ & 412 & & & & Yes & No & \\
\hline
\end{tabular}




\section{CONCLUSION}

We can say that, in absence of constraints, a privilege can be accorded to the cycle 6 . In fact, its predominance is perceptible in the evolution of cycle length according to the operative times, this, while keeping permanent transfer time (see [9]). We are at least sure that this cycle dominates cycles 2 and 4.

In case of constraints and considering the diversity of results found, we notice the utility of a help tool, especially for decision-making in situation of productivity maximization requirement. A wrong choice can have bad consequences: loss of time, damage, rubbish ...

The choice of the cycle 1 remains the more secured and it is optimal when the operative times are relatively small compared to transfer time.

The case study allowed us to test the model and the solution by a practical application in addition to the theoretical example. More over, it encourages us to extend the research for large size problem.

The framework developed in this paper can be extended to more than three machines, of course the number of cycle will increase rapidly, and simulation tool is inevitable for testing the different scenarios.

\section{REFERENCES}

[1] Brauner, N.; Finke, G. (1997). On the Conjecture in Robotic Cells: New Simplified Proof for the Three-Machine Case, Technical report RR 971-PR 982-I, Leisniz-IMAG, Granoble

[2] Brauner, N.; Finke, G. (1999). On cycles and permutations in robotic cells. Internal Note

[3] Sethi, S. P.; Sriskandarajah, C.; Sorger, G.; Blazewicz, J.; Kubiak, W. (1992). Sequencing of parts and robot moves in a robotic cell, International Journal of Flexible Manufacturing Systems, Vol. 4, 331-358

[4] Hall, N. G.; Kammoun, H.; Sriskandarajah, C. (1997). Scheduling in robotic cells: Classification, two and three machine cell, Operations Research, Vol. 45, No. 3, 421-439

[5] Kammoun, H.; Hall, N. G.; Sriskandarajah, C. (1999). Scheduling in robotic cells: Heuristics and cell design, Operations Research, Vol. 47, No. 6, 821-835

[6] Hall, N. G.; Kammoun, H.; Sriskandarajah, C. (1998). Scheduling in robotic cells: Complexity and steady state analysis, European Journal of Operational Research, Vol. 109, Issue 1, 43-65

[7] Sriskandarajah, C.; Hall, N. G.; Kammoun, H. (1998). Scheduling large robotic cells without buffers, Science Publishers, 287-321

[8] Soukhal, A.; Martineau, P. (2005). Resolution of a scheduling problem in a flow shop robotic cell, European Journal of Operational Research, Vol. 161, Issue 1, 62-72

[9] Masmoudi, F.; Masmoudi, Y. (2003). Optimisation des cycles de transfert des produits dans une cellule flexible robotisée. $3^{\text {ème }}$ Conférence Internationale Conception et Production Intégrées, CPI'2003, Meknes, Maroc 